\title{
EVALUATION OF PAROTID GLAND PATHOLOGY BY ULTRASONOGRAPHY AND COMPUTED TOMOGRAPHY IMAGING
}

\author{
Manisha Narayanbhai Solanki ${ }^{1}$ Falguni Ahan Shah², Hemangi Kartik Patel ${ }^{3}$, Sunil Virsingbhai Charpot ${ }^{4}$
}

${ }_{1}^{1}$ Assistant Professor, Department of Radiology, GMERS Sola Medical College and Hospital, Ahmedabad, Gujarat, India. 2 Professor and HOD, Department of Radiology, GMERS Sola Medical College and Hospital, Ahmedabad, Gujarat, India. ${ }^{3}$ Associate Professor, Department of Radiology, GMERS Sola Medical College and Hospital, Ahmedabad, Gujarat, India. ${ }^{4}$ Senior Resident, Department of Radiology, GMERS Sola Medical College and Hospital, Ahmedabad, Gujarat, India.

\author{
ABSTRACT \\ BACKGROUND \\ Ultrasonography (USG) is the first diagnostic procedure to evaluate suspected parotid lesions. USG is capable of differentiating \\ benign and malignant parotid masses. Computed Tomography (CT) is essential for confirmation of diagnosis and preoperative \\ workup in staging of malignancy. \\ Aims and Objectives: \\ 1. To evaluate role of ultrasound and computed tomography in imaging of different parotid gland pathology. \\ 2. To know role of ultrasound and computed tomography imaging in the identification of different parotid gland tumours.
}

\section{MATERIALS AND METHODS}

A retrospective descriptive study of 80 patients was done. Study group consists of patients with parotid gland enlargement, who underwent ultrasonography with or without CT scan. Patients with normal parotid gland on USG are not included in our study. Out of 80 patients of ultrasonography having parotid gland enlargement, 36 patients underwent CT scan.

\section{RESULTS}

Out of 80 patients, most common pathology was infective or inflammatory origin and $98 \%$ sensitivity and specificity was seen Second most common pathology was benign neoplasm where sensitivity was $88 \%$, while specificity was $84 \%$. 43 patients were found to have infective or inflammatory aetiology. 31 patients had neoplasm, among them, 22 patients had benign masses and 8 patients had primary malignant masses and 1 patient had intraparotid metastatic lymph node. Only 1 patient had congenital vascular pathology. In malignant masses, sensitivity and specificity were $80 \%$.

\section{CONCLUSION}

Ultrasonography is the basic modality for parotid gland pathology and CT scan is the investigation of choice for parotid masses to confirm benign nature by the pattern of vascular enhancement and staging of malignancies of parotid gland.

\section{KEY WORDS}

Parotid Gland, Ultrasonography, Parotid Masses, Computed Tomography

HOW TO CITE THIS ARTICLE: Solanki MN, Shah FA, Patel HK, et al. Evaluation of parotid gland pathology by ultrasonography and computed tomography imaging. J. Evolution Med. Dent. Sci. 2019;8(10):696-700, DOI: 10.14260/jemds/2019/154

\section{BACKGROUND}

Parotid gland is the largest salivary gland. It is located in the retromandibular fossa. Parotid gland pathology is divided into congenital, inflammatory, infective, benign and malignant neoplastic masses.

Sonography is the first imaging modality for evaluating parotid gland due to portability, easy to use, non-ionising, repeatability, real time dynamic study and less expensive as well as for follow-up comparison over and above role in Fine Needle Aspiration Cytology (FNAC).

'Financial or Other Competing Interest': None.

Submission 17-07-2018, Peer Review 09-10-2018,

Acceptance 17-10-2018, Published 11-03-2019.

Corresponding Author:

Dr. Falguni Ahan Shah,

Professor and HOD,

Department of Radiology,

Block-B, GMERS Medical College and Hospital, Sola,

Near Gujarat High Court, S. G. Highway,

Ahmedabad-380060,

Gujarat, India.

E-mail: tathagat2000@yahoo.co.in

DOI: $10.14260 /$ jemds $/ 2019 / 154$

\section{(c) $(1) \ominus$}

Ultrasonography with the help of high-frequency linear transducer, colour Doppler and pulse wave Doppler mode is excellent for evaluating parotid pathology. However, deep lobe of parotid gland is sometimes difficult to evaluate on sonography, more in obese patients and having malignant mass in relation to deep lobe.

CT and Magnetic Resonance Imaging (MRI) are useful for detailed evaluation and deeper extension of the masses as well as staging of malignant tumour. The high sensitivity of CT/ MRI, which approaches $100 \%$ for detecting parotid neoplasms. ${ }^{1}$ CT scan is excellent to detect bony invasion and calcification. However, on CT, low-grade mucoepidermoid carcinoma is difficult to differentiate from pleomorphic adenoma.

\section{Aims and Objectives}

1. To evaluate role of ultrasound and computed tomography in imaging of different parotid gland pathology for early diagnosis and for line of management.

2. To know sensitivity and specificity of ultrasound and computed tomography imaging in the identification of different parotid gland tumours. 


\section{MATERIALS AND METHODS}

\section{Study Design}

Retrospective descriptive study.

During the period from April 2016 to October 2017, a retrospective study of 80 patients was carried out. The study group consisted of patients from GMERS Sola Hospital with positive sonographic findings for parotid pathology. All the radiologists of Radiology Department have made substantial contributions by team work for this study. Sonography was done with high resolution linear transducer on Philips Affiniti 80 and Mindray DC-N3. Detailed history and presenting symptoms was evaluated. Ultrasound was performed on the patient in the supine position. A direct contact scanning technique with the use of the acoustic coupling gel was used and scanning was done in the sagittal, transverse, coronal and oblique sections. Diagnosis was confirmed by clinical correlation and by follow-up sonography. Histopathological diagnosis was done selectively in operated cases. All patients did not undergo other radiological and/ or required pathological investigations like FNAC and/ or biopsy. Patients with clinically suspected parotid pathology that turned out normal parotid on sonography and having extra parotid lesions and those patients who could not be followed up till the final diagnosis were not included in our study. Data analysis was done with the help of Microsoft Excel.

\section{RESULTS}

In the present study, out of 80 patients 45 were males and 35 were females.

Out of 80 patients, most common pathology was infective or inflammatory origin and $98 \%$ sensitivity and specificity was seen. Second most common pathology was benign neoplasm, where sensitivity was $88 \%$ while specificity was $84 \%$. 43 patients were found to have infective or inflammatory aetiology. 31 patients had neoplasm, among them 22 patients had benign masses and 8 patients had primary malignant masses and 1 patient had intraparotid metastatic lymph node. Only 1 patient had congenital vascular pathology. In malignant mass, sensitivity and specificity were $80 \%$.

\begin{tabular}{|c|c|c|c|}
\hline Age Group & No. of Male Patients & No. of Female Patients & Total No. of Patients \\
\hline Infants to 10 Yrs. & 2 & 1 & 3 \\
\hline 11 to 20 Yrs. & 5 & 3 & 8 \\
\hline 21 to 30 Yrs. & 9 & 8 & 17 \\
\hline 31 to 40 Yrs. & 9 & 11 & 20 \\
\hline 41 to 50 Yrs. & 10 & 7 & 17 \\
\hline 51 to 60 Yrs. & 5 & 3 & 8 \\
\hline 61 to 70 Yrs. & 4 & 2 & 6 \\
\hline 71 to 80 Yrs. & 1 & 0 & 1 \\
\hline Total & 45 (56.2\%) & $\mathbf{3 5}$ (43.7\%) & $\mathbf{8 0}$ \\
\hline \multicolumn{2}{r}{} \\
\hline
\end{tabular}

\begin{tabular}{|c|c|c|c|c|c|c|}
\hline & \multicolumn{2}{|c|}{ Diagnosis } & & No. of Cases & Total & $\%$ \\
\hline \multirow{2}{*}{1} & \multirow{2}{*}{\multicolumn{2}{|c|}{ Congenital }} & Haemangioma & \begin{tabular}{|l|}
1 \\
\end{tabular} & \multirow{2}{*}{1} & \multirow{2}{*}{1.25} \\
\hline & & & Lymphangioma & - & & \\
\hline \multirow{3}{*}{2} & \multirow{3}{*}{\multicolumn{2}{|c|}{ Infection and Inflammation }} & Parotitis & 31 & \multirow{3}{*}{43} & \multirow{3}{*}{53.7} \\
\hline & & & Parotitis with Abscess & 10 & & \\
\hline & & & Chronic Parotitis & 2 & & \\
\hline \multirow{6}{*}{3} & \multirow{6}{*}{$\begin{array}{c}\text { Neoplasm } \\
\text { (31 patients - } \\
38.7 \%)\end{array}$} & \multirow{4}{*}{ Benign } & Pleomorphic Adenoma & 18 & \multirow{4}{*}{22} & \multirow{4}{*}{27.5} \\
\hline & & & Warthin's Tumour & 4 & & \\
\hline & & & Lipoma & - & & \\
\hline & & & Schwannoma & - & & \\
\hline & & \multirow{2}{*}{ Malignant } & Primary Malignant Mass & 8 & \multirow{2}{*}{9} & \multirow{2}{*}{11.2} \\
\hline & & & Secondary Intraparotid Metastatic Lymph Node & 1 & & \\
\hline \multirow{3}{*}{4} & \multirow{3}{*}{\multicolumn{2}{|c|}{ Miscellaneous }} & Lymphoepithelial Lesions Associated Immuno-Compromised Patient & 1 & \multirow{3}{*}{5} & \multirow{3}{*}{6.25} \\
\hline & & & Intraparotid Sinus Tract & 1 & & \\
\hline & & & Intraductal Obstructing Calculus & 3 & & \\
\hline \multicolumn{4}{|r|}{ Total Number of Patients } & \multirow{2}{*}{\multicolumn{3}{|c|}{80}} \\
\hline & & & Table 2. Types and Distribution of Parotid Lesions & & & \\
\hline
\end{tabular}

\begin{tabular}{|c|c|c|c|c|}
\hline & Congenital & Infective/ Inflammatory & Benign Lesion & Malignant \\
\hline $\begin{array}{c}\text { Gland Enlargement with Generalised Increase in } \\
\text { Vascularity of Gland }\end{array}$ & - & 41 & - & - \\
\hline Dilated Ducts & - & 3 & - & - \\
\hline Abscess Formation in Gland & - & 10 & - & - \\
\hline Cystic Masses & - & 1 & 1 & 2 \\
\hline Solid Mass Lesion with Well-Defined Smooth Margin & - & - & 22 & 2 \\
\hline Solid Mass Lesion with Ill-Defined Irregular Margin & 1 & - & - & 6 \\
\hline Calcifications or Phlebolith & 1 & - & 2 & 3 \\
\hline Calculus & 3 & - & - & - \\
\hline Focal Increase Vascularity in Solid Mass & 1 & - & 22 & 8 \\
\hline Lymph Nodes & - & 31 & 6 & 5 \\
\hline
\end{tabular}




\begin{tabular}{|c|c|c|}
\hline & Benign & Malignant \\
\hline Hypodense Mass & 22 & 6 \\
\hline Hyperdense Mass & - & 2 \\
\hline Well-Defined Margin & 21 & 3 \\
\hline Ill-Defined Margin & 1 & 5 \\
\hline Homogeneous Enhancement & 16 & 3 \\
\hline Heterogeneous Enhancement & 6 & 5 \\
\hline Low Enhancement & 5 & 2 \\
\hline Intense Enhancement & 17 & 6 \\
\hline Necrosis & 3 & 5 \\
\hline Cystic Component & 3 & 3 \\
\hline Fat Density & - & - \\
\hline Calcification & 4 & 3 \\
\hline Lymph Nodes & 15 & 7 \\
\hline
\end{tabular}

\begin{tabular}{|l|l|}
\hline Figure 1. Acute Parotitis: Ultrasonography of Right Parotid Gland (a) B-Mode Shows Generalised Enlargement of Gland \\
with Altered Echo Texture. (b) On Colour Doppler Mode Shows Prominent Vascularity
\end{tabular}

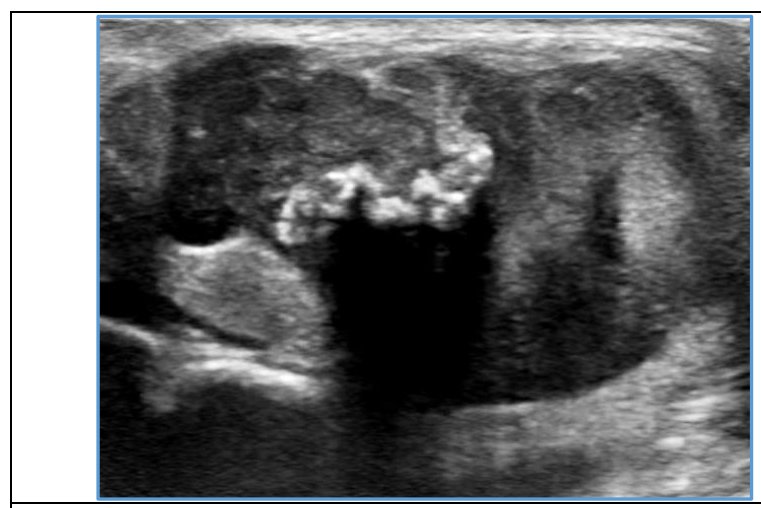

Figure 2. Pleomorphic Adenoma: Ultrasonography of Right Parotid Gland Shows Well-Defined, Lobulated, Hypoechoic Lesion with Coarse Calcification Within It

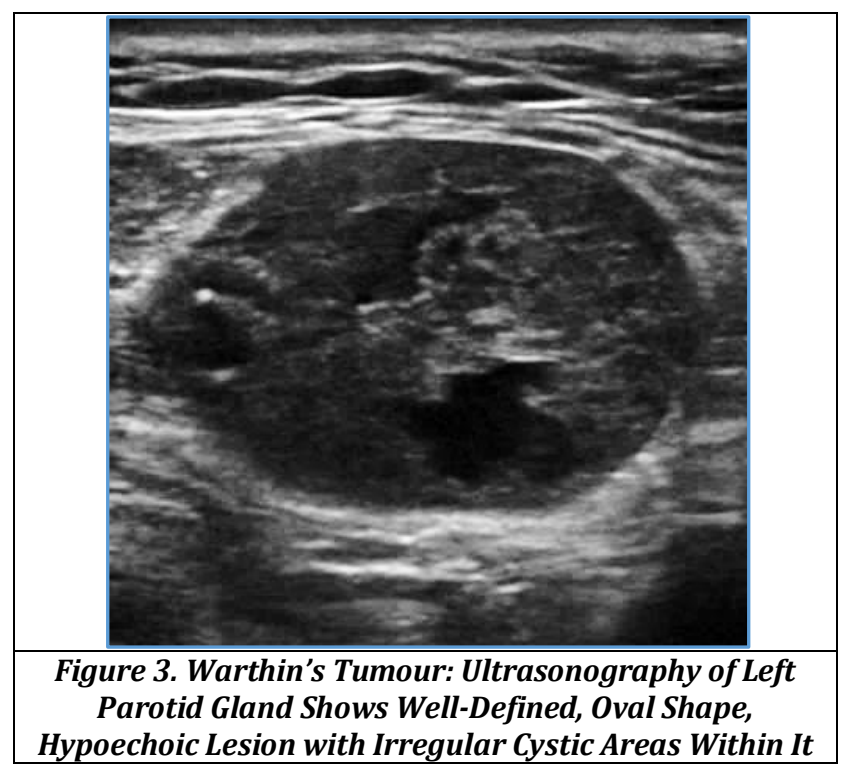

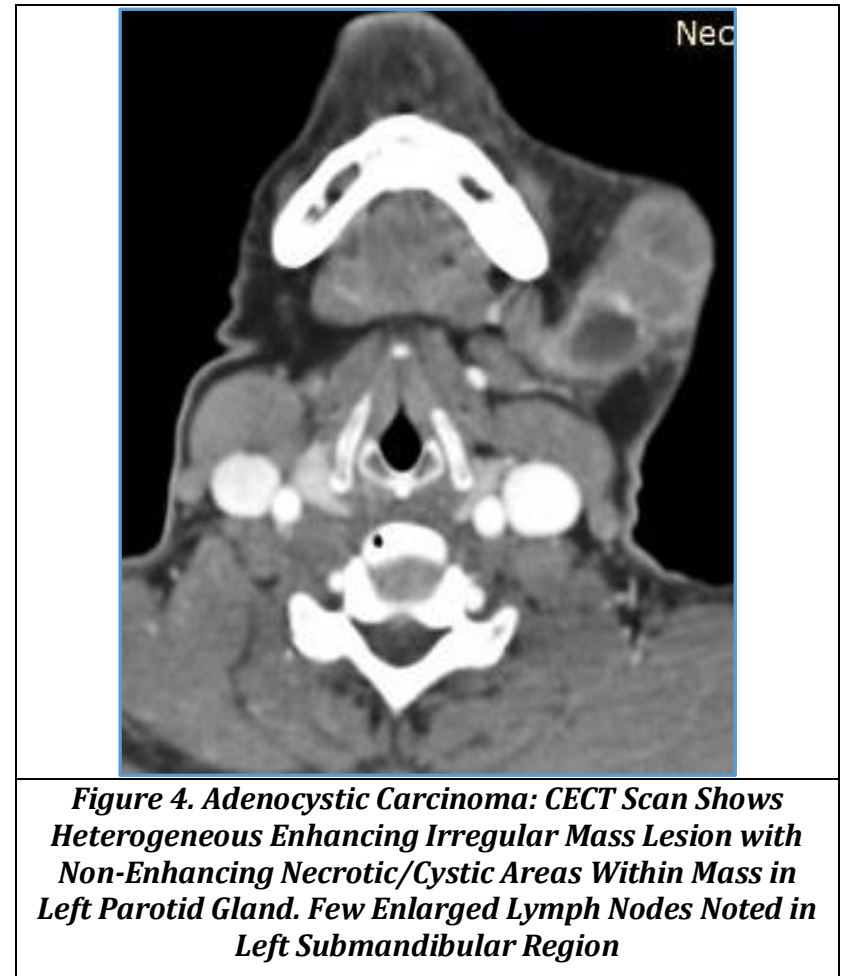



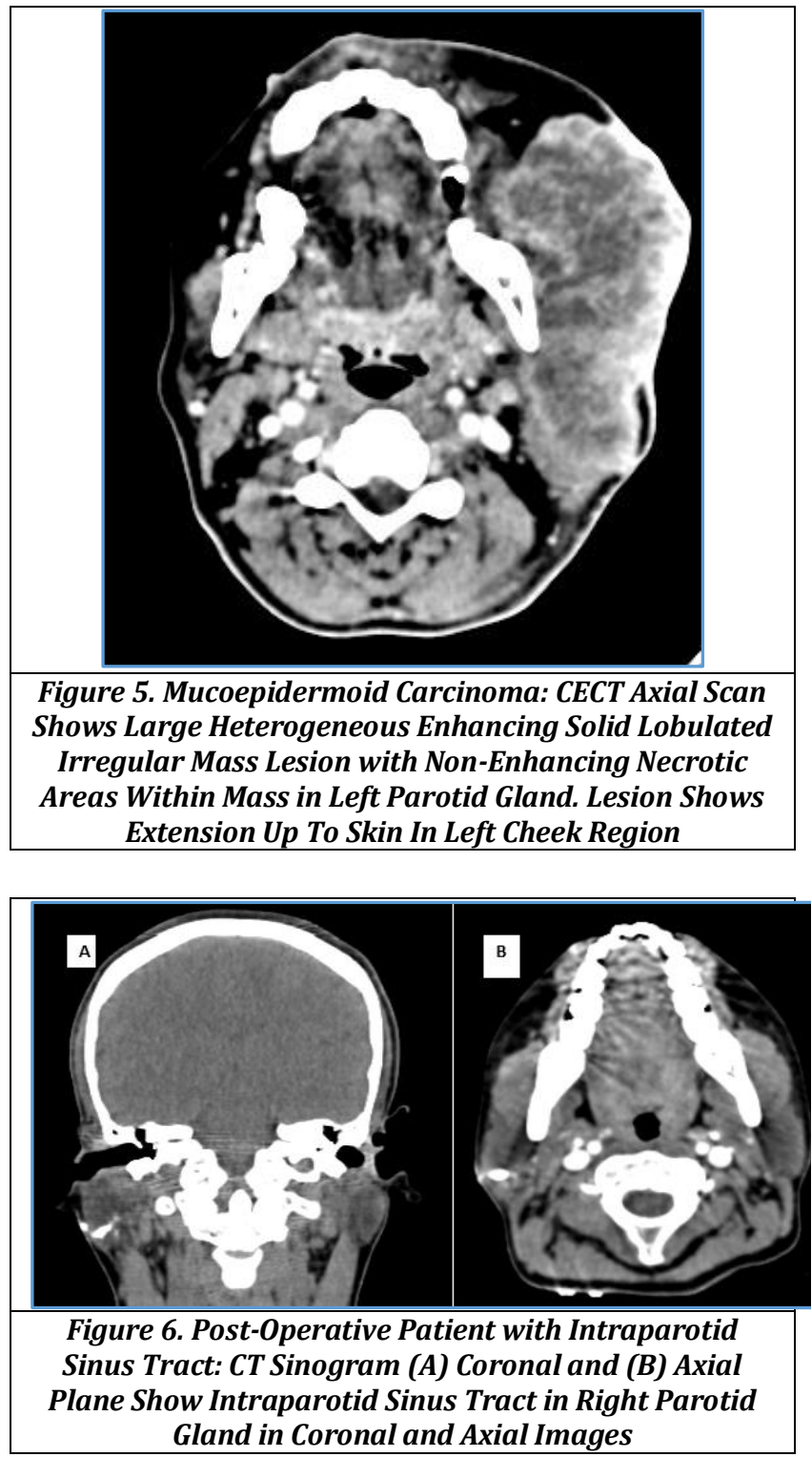

\section{DISCUSSION}

Acute parotitis is the most common lesion of parotid gland.2,3 In sonography, findings are diffuse enlarged hypoechoic gland with prominent internal vascularity. Inflammatory lymphadenopathy may be seen in neck.

Abscess formation may be seen in patient with acute parotitis. Abscess appears hypoechoic or anechoic lesion with irregular shape and posterior acoustic enhancement noted in sonography.

Sialolithiasis of parotid gland noted in about $10 \%-20 \%$ of cases. ${ }^{4}$ On sonography, calculus was seen as hyperechoic focus with distal acoustic shadowing. Associated findings are dilated intraparotid and excretory ducts. CT allows visualisation of large stones, but without their precise localisation and without the possibility of assessment of the ducts.

Benign tumours are more common than malignant tumour in parotid gland.

Pleomorphic adenoma is the most common benign tumour of parotid gland (80\%).5,6 It is more commonly seen in females of middle age group. Warthin's tumour is the second most common parotid tumour, predominantly seen in male patient in $6^{\text {th }}$ decade. ${ }^{7,8}$ Sonographic findings are oval heterogeneous hypoechoic mass, cystic component may be seen. Usually $1-4$ $\mathrm{cm}$ in size and predominantly seen in parotid tail region. Moderate enhancement was noted on CT study.

Malignant parotid lesions are much less common than benign lesions. ${ }^{9}$ Mucoepidermoid carcinoma is the most common parotid gland malignancy. This typically large tumour tends to have lobulated borders and moderate hyperdensity. Adenocystic carcinoma is the second most common malignancy of the parotid gland. ${ }^{9}$ The sonographic criteria for malignant parotid mass are heterogeneous echo texture with cystic component, non-compressibility, illdefined or speculated margin, punctate calcification and prominent vascularity and in advanced cases extension to skin and surrounding soft tissue is also seen. In metastatic lymphadenopathy lymph nodes show loss of central hilum with altered echo pattern, irregular margin and necrosis.

Haemangiomas are most common tumours in infants. On imaging, it appears as heterogeneous lesions with sinusoidal spaces and phleboliths as tiny calcifications. ${ }^{10}$

Other lesions of parotid glands are tuberculosis, lipomas, first branchial cleft cysts, schwannomas, collagen vascular disease such as Sjogren's syndrome, sarcoidosis like granulomatous disease and lymphoepithelial lesions associated with immune compromised status.

In present study, parotid gland pathology is classified into congenital, infective/ inflammatory, benign tumours, malignant tumours and miscellaneous conditions.

In present study, males are more affected than females. Middle age group are more commonly affected.

The most common parotid pathology is parotitis. Out of 80 patients, 43 (53.7\%) patients had parotitis. Among them 32 patients had acute parotitis and 10 patients had parotitis with abscess formation. Parotitis is common in all age groups without any sex predilection.

In this study, second most common pathology is benign mass. Out of 80 patients, $22(27.5 \%)$ patients had benign mass. Pleomorphic adenoma is the most common tumour in neoplastic lesions. Out of 22 patients of benign neoplasm of parotid gland, 18 patients $(81.8 \%)$ had pleomorphic adenoma. While Warthin's tumour is the second most common tumour among benign tumours, which is similar to Renehan et al study.

In our study, pleomorphic adenoma is commonly seen in females and especially in middle age group. Characteristic sonographic findings of pleomorphic adenomas are homogeneous hypoechoic, well-defined margin, lobulated shape, low vascularity and posterior acoustic enhancement ${ }^{11,12}$ which are similar with our sonographic findings.

Malignant parotid tumours are less common and only $11.2 \%$ are seen in our study, which correlate with Lin et al study. ${ }^{13}$ Out of 31 patients of neoplastic lesion, only 8 patients (25\%) had primary malignant tumour.

We have 8 patients of primary malignant tumour, out of them 5 patients $(62.5 \%)$ had mucoepidermoid carcinoma and $3(37.5 \%)$ patients had adenocystic carcinoma on histology report. The most common type of malignant tumour was mucoepidermoid carcinoma, which is similar with some other studies. ${ }^{13,14}$

On the basis of ultrasound, it is difficult to differentiate between benign and low-grade malignant parotid masses. FNAC or core biopsy is the confirmative for diagnosis. 
In the present study only one patient was misdiagnosed as pleomorphic adenoma, because of small size $(2-3 \mathrm{~cm})$, welldefined hypoechoic border with low vascularity, but it turned out to be mucoepidermoid carcinoma on histopathological examination.

The sonographic characteristics of parotid masses including shape, margin, echogenicity, echo texture and vascularisation between benign and malignant lesions had no significant difference, which indicated that it is hard to distinguish malignant parotid masses from benign masses using sonography and that this method is unable to distinguish between different benign or malignant lesions, because some tumours and lesions have similar characteristics. ${ }^{15-17}$

Colour Doppler flow imaging may find parotid masses blood supply information, but the distribution in benign and malignant lesions had no significant difference and its value was limited which was consistent with Bradley et al ${ }^{18}$ and Schick et al. ${ }^{19}$

In Mohammed et al ${ }^{20}$ study, out of 242 patients 183 (75.6\%) had benign neoplasms, 51 (21.1\%) had malignant neoplasms and $8(3.3 \%)$ had inflammatory or lymphatic lesions. While in our study, inflammatory conditions are the most common (53.7\%) conditions followed by benign neoplasm (27.5\%) and then malignant neoplasm (11.2\%).

In our study, benign and inflammatory lesion sensitivity was more than $99 \%$.

While parotid mass lesion sensitivity was also more than $99 \%$, but specificity was $90 \%$ due to one female suspected as benign mass on CT scan was turned out to be malignant on FNAC.

\section{CONCLUSION}

On comparing the sonographic diagnosis of parotid gland masses with the pathological results, it was found that the sensitivity, specificity, positive predictive value, negative predictive value and accuracy with USG in differentiating inflammatory/ infective pathology and from neoplastic mass including lipoma, haemangioma is very high.

But it is challenging to diagnose or differentiate between benign and malignant parotid gland masses with USG and CT scan or both, where FNAC gives the final answer.

In staging of advanced malignant parotid mass, CT scan has got definite role.

To make a definite diagnosis in benign tumour from early, small or low-grade malignancy, ultrasound-guided FNAC is suggested for confirmation.

\section{REFERENCES}

[1] Bron LP, Traynor SJ, McNeil EB, et al. Primary and metastatic cancer of the parotid: comparison of clinical behavior in 232 cases. Laryngoscope 2003;113(6):1070-5.

[2] Rabinov JD. Imaging of salivary gland pathology. Radiol Clin North Am 2000;38(5):1047-57.

[3] Silvers AR, Som PM. Salivary glands. Radiol Clin North Am 1998;36(5):941-66.

[4] Zenk J, Constantinidis J, Kydles S, et al. Clinical and diagnostic findings of sialolithiasis [in German]. HNO 1999;47(11):963-9.
[5] Pollei SR, Harnsberger HR. The radiologic evaluation of the parotid space. Semin Ultrasound CT MR 1990;11(6):486-503.

[6] Wenig BM. Neoplasms of the salivary glands. In: Wenig BM, edr. Atlas of head and neck pathology. Philadelphia: WB Saunders 1993: p. 283-334.

[7] Renehan A, Gleave EN, Hancock BD, et al. Long-term follow-up of over 1000 patients with salivary gland tumours treated in a single centre. $\mathrm{Br} \mathrm{J}$ Surg 1996;83(12):1750-4.

[8] Ellis GL, Auclair PL, Gnepp DR. Surgical pathology of the salivary glands. Philadelphia, Pa: Saunders 1991.

[9] Joseph LKT, Stuart SS, Robert SJ, et al. Computed body tomography with MRI correlation. Vol. 1. $4^{\text {th }}$ edn. Lippincott Williams \& Wilkins 2005: p. 154, 155.

[10] Wong KT, Ahuja AT, King AD, et al. Vascular lesions of parotid gland in adult patients: diagnosis with highresolution ultrasound and MRI. $\mathrm{Br} J$ Radiol 2004;77(919):600-6.

[11] Colella G, Cannavale R, Flamminio F, et al. Fine needle aspiration cytology of salivary gland lesions: a systematic review. J Oral Maxillofac Surg 2010;68(9):2146-53.

[12] Bialek EJ, Jakubowski W, Karpinska G. Role of ultrasonography in diagnosis and differentiation of pleomorphic adenomas: work in progress. Arch Otolaryngol Head Neck Surg 2003;129(9):929-33.

[13] Lin CC, Tsai MH, Huang CC, et al. Parotid tumors: a 10year experience. Am J Otolaryngol 2008;29(2):94-100.

[14] Takahama A Jr, Almeida OP, Kowalski LP. Parotid neoplasms: analysis of 600 patients attended at a single institution. Braz J Otorhinolaryngol 2009;75(4):497501.

[15] Yasumoto M, Yoshimura R, Sunaba K, et al. Sonographic appearances of malignant lymphoma of the salivary glands. J Clin Ultrasound 2001;29(9):491-8.

[16] Zacharia TT, Ittoop A, Perumpillichira JJ, et al. Sonographic appearance of a congenital parotid gland hemangiolymphangioma simulating malignancy in an infant. J Clin Ultrasound 2003;31(9):493-6.

[17] Eichhorn KW, Arapakis I, Ridder GJ. Malignant nonHodgkin's lymphoma mimicking a benign parotid tumor: sonographic findings. J Clin Ultrasound 2002;30(1):42-4.

[18] Bradley MJ, Durham LH, Lancer JM. The role of colour flow Doppler in the investigation of the salivary gland tumour. Clin Radiol 2000;55(10):759-62.

[19] Schick S, Steiner E, Gahleitner A, et al. Differentiation of benign and malignant tumors of the parotid gland: value of pulsed Doppler and color Doppler sonography. Eur Radiol 1998;8(8):1462-7.

[20] Mohammed F, Asaria J, Payne RJ, et al. Retrospective review of 242 consecutive patients treated surgically for parotid gland tumours. J Otolaryngol Head Neck Surg 2008;37(3):340-6. 